Published in final edited form as:

Vaccine. 2014 October 29; 32(47): 6259-6265. doi:10.1016/j.vaccine.2014.09.007.

\title{
The Vaccination Confidence Scale: A Brief Measure of Parents' Vaccination Beliefs
}

\author{
Melissa B. Gilkey, $\mathrm{PhD}^{\mathrm{a}}$, Brooke E. Magnus, $\mathrm{MA}^{\mathrm{b}}$, Paul L. Reiter, $\mathrm{PhD}^{\mathrm{c}}$, Annie-Laurie \\ McRee, DrPH ${ }^{d}$, Amanda F. Dempsey, MD, PhD, MPH ${ }^{e}$, and Noel T. Brewer, PhD ${ }^{f}$ \\ Melissa B. Gilkey: gilkey@email.unc.edu; Brooke E. Magnus: brooke.magnus@unc.edu; Paul L. Reiter: \\ paul.reiter@osumc.edu; Annie-Laurie McRee: mcree.1@osu.edu; Amanda F. Dempsey: \\ amanda.dempsey@ucdenver.edu; Noel T.Brewer: ntb@unc.edu \\ aLineberger Comprehensive Cancer Center, University of North Carolina; CB 7440; Chapel Hill, \\ NC 27599 USA \\ bDepartment of Psychology, University of North Carolina; CB 3270; Chapel Hill, NC 27599 USA \\ 'Division of Cancer Prevention and Control, The Ohio State University; 1590 North High Street, \\ Ste. 525; Columbus, OH 43201 USA \\ dDepartment of Health Behavior and Health Promotion, The Ohio State University; 354 Cunz Hall, \\ 1841 Neil Ave; Columbus, OH 43210 USA \\ eChilden's Outcomes Research Program, University of Colorado Denver; 13199 E Montview Blvd; \\ Mail Stop F443; Aurora, CO 80045 USA \\ fDepartment of Health Behavior, University of North Carolina; CB 7440; Chapel Hill, NC 27599 \\ USA; Phone: 919-966-3282; Fax: 919-966-2921
}

\section{Abstract \\ Purpose-The success of national immunization programs depends on the public's confidence in vaccines. We sought to develop a scale for measuring confidence about adolescent vaccination in diverse populations of parents.}

Methods-Data came from 9,623 parents who completed the 2010 National Immunization Survey-Teen, an annual, population-based telephone survey. Parents reported on a 13- to 17-yearold child in their households. We used exploratory and confirmatory factor analysis to identify latent constructs underlying parents' responses to 8 vaccination belief survey items (response scale 0-10) conceptualized using the Health Belief Model. We assessed the scale's psychometric properties overall and across demographic subgroups.

Results-Parents' confidence about adolescent vaccination was generally high. Analyses provided support for three factors assessing benefits of vaccination (mean $=8.5)$, harms of vaccination $($ mean $=3.3)$, and trust in healthcare providers $($ mean $=9.0)$. The model showed good

(C) 2014 Elsevier Ltd. All rights reserved.

Publisher's Disclaimer: This is a PDF file of an unedited manuscript that has been accepted for publication. As a service to our customers we are providing this early version of the manuscript. The manuscript will undergo copyediting, typesetting, and review of the resulting proof before it is published in its final citable form. Please note that during the production process errors may be discovered which could affect the content, and all legal disclaimers that apply to the journal pertain. 
fit both overall (comparative fit index $=0.97$ ) and across demographic subgroups, although internal consistency was variable for the three factors. We found lower confidence among several potentially vulnerable subpopulations, including mothers with lower levels of education and parents whose children were of Hispanic ethnicity (both $p<.05$ ).

Conclusions-Our brief, three-factor scale offers an efficient way to measure confidence in adolescent vaccination across demographic subgroups. Given evidence of lower confidence by educational attainment and race/ethnicity, program planners should consider factors such as health literacy and cultural competence when designing interventions to promote adolescent vaccination to ensure these programs are fully accessible.

\section{Keywords}

adolescent health; vaccine hesitancy; meningococcal vaccine; human papillomavirus vaccine; tetanus vaccine; immunization

\section{INTRODUCTION}

Parents' confidence in vaccines is critical to the success of national immunization programs. Unfortunately, in the case of adolescent vaccines, recent research suggests that many parents are not convinced that the benefits of vaccination outweigh the costs. For example, over $30 \%$ of parents in the U.S. report having refused or delayed human papillomavirus (HPV) vaccine for their adolescent daughters; their reasons include doubts about safety, effectiveness, and whether the vaccine is needed [1]. Parents who have not gotten their children tetanus, diphtheria, and acellular pertussis (Tdap) or meningococcal vaccines also commonly report believing these vaccines are not necessary [2]. Increasing parents' confidence in the value of adolescent vaccination is important for addressing parental refusal and delay, especially since adolescent vaccines have yet to attain the high coverage achieved for many early childhood vaccines [3].

Better measures of vaccination confidence could facilitate research and interventions aimed at addressing hesitancy toward adolescent vaccines. Although scales have been developed for specific vaccines [4] or for parents of younger children [5], the field currently lacks a composite measure capable of characterizing adolescent vaccination beliefs more holistically. Because research indicates that vaccine hesitancy varies by demographic characteristics [1,5-8], a scale that could perform reliably across diverse populations would be especially valuable.

To address this need, we developed the Vaccination Confidence Scale using data from a national, population-based sample of parents of adolescent children. To test the suitability of our scale for use in diverse populations, we assessed the scale's properties by demographic factors including race/ethnicity, maternal educational attainment, and household income. Finally, we used the scale to assess subgroup differences in vaccination confidence. 


\section{METHODS}

\section{Participants and Data Source}

We used existing data from the 2010 National Immunization Survey (NIS)-Teen, an annual, population-based survey sponsored by the Centers for Disease Control and Prevention [9]. Data collection included a telephone survey of respondents contacted through random digit dialing. Eligible respondents were parents or guardians who provided information about a randomly selected 13- to 17-year-old child in their household. For the sake of simplicity, we refer to these participants hereafter as "parents."

The household response rate for the 2010 NIS-Teen, excluding the U.S. Virgin Islands, was $58 \%$, and resulted in an overall sample of 32,429 parents from all 50 states and select localities, including the District of Columbia. Data for this study came from a subset of 11,754 parents who completed the "Parental Attitudes Module," a special addendum administered in 2010 for two of the four quarters during which NIS-Teen data were collected. We excluded parents who did not provide responses to key variables $(n=1,282)$, who took the survey in a language other than English $(n=607)$, or who were dropped due to weighting procedures $(n=242)$. Our final analytic sample consisted of 9,623 parents.

The National Center for Health Statistics (NCHS) Research Ethics Review Board approved data collection for NIS-Teen. Analysis of deidentified data from the survey is exempt from the federal regulations for the protection of human research participants. Analysis of restricted data through the NCHS Research Data Center was approved by the NCHS Ethics Review Board. The University of North Carolina Institutional Review Board ruled this study exempt from further review.

\section{Measures}

The Parental Attitudes Module assessed 11 beliefs about the vaccination of teenagers using an 11-point response scale that ranged from 0 ("strongly disagree") to 10 ("strongly agree"). Items were conceptualized using the Health Belief Model, a theory of health behavior that researchers have successfully used to identify attitudes related to vaccination in early childhood and adolescence [7,10]. Topics included perceived benefits of vaccination such as disease prevention and perceived barriers to vaccination such as side effects (Figure 1).

Given the extent to which prior research emphasizes the importance of trust in vaccination decisions [5,7,11-13], we included two items from the Parental Attitudes Module that assessed parents' relationship with healthcare providers, including one general item that was not specific to vaccination. Because items in the Parental Attitudes Module are restricted variables that are not included in the 2010 NIS-Teen public-use dataset, we accessed these data through the NCHS Research Data Center.

The 2010 NIS-Teen also assessed demographic characteristics including the child's age, sex, and race/ethnicity (Table 1). The survey assessed variables used to determine whether the child was eligible for the Vaccines for Children (VFC) Program, which provides free vaccines to populations with limited ability to pay, including uninsured and Medicaideligible youth [14]. Respondents indicated their own relationship to the child as well as the age and educational attainment of the child's mother. Household characteristics included 
annual income and geographic location. We classified households as urban, suburban, or rural based on metropolitan statistical areas [15].

\section{Statistical Analysis}

We used factor analysis to identify the latent constructs underlying parents' responses to the 11 items on vaccination beliefs in the Parental Attitudes Module. First, we randomly selected a subset comprising half of the entire sample to conduct an exploratory factor analysis (EFA). We used principal factor extraction followed by oblique rotation, which allows correlation among the factors. We fit one-, two-, three-, and four-factor models, examining factor loadings for each model. We retained models for further analysis based on the following criteria: 1) number of factors with eigenvalues $>1$; 2) change in the curve of the scree plot; 3 ) signs of under-factoring (i.e., several items showing loadings $>0.40$ on more than one factor); 4) signs of over-factoring (i.e., several items showing loadings $<0.30$ on all factors); and 5) likelihood ratio tests between models [16]. To create the most parsimonious scale possible, we examined each survey item individually and removed items from further analyses if they failed to load meaningfully on any factor $($ i.e., loading < .30).

Next, for each of the retained models, we performed a confirmatory factor analysis using the full sample. For multi-factor models, we matched subsets comprising 2-3 items each with the factors and fixed all other factor loadings to zero, resulting in a simple structure. To assess model fit, we used the root mean square error of approximation (RMSEA), which is a measure of how well the model is able to reproduce the observed correlations between the items on the scale, and the comparative fit index (CFI), which measures the degree to which the proposed model is superior to a model that assumes that all of the items on the scale are uncorrelated. We used guidelines of RMSEA $\leq 0.05$ and CFI $\geq 0.95$ to indicate highly acceptable, or "excellent" fit; we used RMSEA $\leq 0.06$ and CFI $\geq 0.90$ to indicate acceptable, or "good" fit $[17,18]$. For each model, we also conducted chi-squared goodness of fit tests for the entire sample and for each demographic subgroup. We compared the fits of candidate models using likelihood-ratio tests.

We used classical test theory methods to examine item performance for each candidate model. These methods, which included calculating coefficient alpha for each item as well as item-deleted alphas, help verify that each item contributes to the measurement of the latent constructs and that no single item detracts from overall scale reliability. We conducted these analyses using the full sample and for each demographic subgroup to verify that items performed similarly across variables prior research indicates may be associated with vaccination beliefs, refusal and delay. These variables included adolescent demographics (age, sex, race/ethnicity, VFC eligibility), mother's educational attainment, household income, and MSA status [1,5-8].

For each model, we calculated mean factor scores (range: 0-10) by averaging the item responses within a particular factor. To assess how adolescent vaccination beliefs vary across populations, we also calculated mean factor scores for each demographic subgroup. For each grouping variable (e.g., sex, race/ethnicity, etc.), we used $t$-tests to assess whether sub-groups within that category differed from a reference group. We report raw frequencies 
and weighted means and percentages. All statistical analyses were conducted in SAS 9.3 (Cary, NC).

\section{RESULTS}

\section{Sample}

The mean age for children was 15.0 years, with similar numbers of males (51\%) and females (49\%) (Table 1). Most parents reported on children who were non-Hispanic white (66\%), non-Hispanic black (16\%), or Hispanic (11\%). About one-third (34\%) of teens had a mother with a high school degree or less education, and over one-tenth (14\%) of teens lived in households with annual incomes below the poverty level.

\section{Factor Analysis}

Exploratory analysis-The results of the exploratory factor analysis yielded two candidate scales: a one-factor scale and a three-factor scale. The scales had 8 items, after dropping 3 items ("My teenager helps make the decision about whether he or she will receive a vaccine," "I make a point to read and watch stories about health," and "Vaccination should be delayed if a teenager has a minor illness") because they did not meaningfully load onto any factor.

Confirmatory analysis of 1-factor scale-For the one-factor scale, we reverse-coded negative attitudes and labeled the resulting factor "General Confidence," corresponding to positive parental attitudes toward adolescent vaccination (Figure 1, left side). Coefficient alpha for this general scale was 0.77 overall (Table 2), and in stratified analyses, values ranged from 0.70 to 0.80 across demographic subgroups (data not shown). The model showed marginally acceptable fit: $\chi^{2}(20)=1367, p<0.001$; CFI $=0.93$; RMSEA $=0.08$. Standardized factor loadings ranged from 0.31 to 0.73 (all $p<.05$, Table 2 ).

Confirmatory analysis of 3-factor scale-The three-factor scale had factors with more specific interpretations (Figure 1, right side). The first factor, "Benefits," consisted of four items related to the potential advantages and safety of vaccinating one's teenager that was reliable for the overall sample and all subgroups we examined (overall $a=0.78$; range across subgroups: 0.72-0.80). The second factor, "Harms," comprised two items about perceived negatives related to adolescent vaccination, including possible side effects (overall $a=0.49$; range: $0.45-0.54$ ). The third factor, "Trust," comprised two items relating to the parent and healthcare provider relationship (overall $a=0.51$; range: $0.43-0.55$ ).

The model for the three-factor scale showed good fit: $\chi^{2}(17)=550$; CFI $=0.97$; RMSEA $=$ 0.06 . For the entire sample and for all 22 sub-groups within the sample, likelihood-ratio tests indicated that the three-factor model exhibited better fit than the one-factor model, as shown by the large $\Delta \chi^{2}$ statistics (Table 3). Standardized factor loadings ranged from 0.41 to 0.84 (all $p<.05$, Table 2) and were equal or larger in size than those achieved for the one-factor scale.

All factors in the three-factor scale correlated in the expected directions (Figure 1). Harms and Benefits were strongly negatively correlated $(r=-0.73, \mathrm{SE}=0.01)$. Benefits and Trust 
were strongly positively correlated $(r=0.69, \mathrm{SE}=0.01)$. Harms and Trust were moderately negatively correlated $(r=-0.49, \mathrm{SE}=0.02)$.

\section{Confidence among Demographic Subgroups}

Overall confidence in adolescent vaccination was generally high (one-factor scale: $M=8.15$, $S E=0.02)$ (Table 4). However, in stratified analyses of the one-factor scale, we found evidence of less favorable vaccination beliefs among several subpopulations: parents of adolescents of Hispanic versus non-Hispanic white ethnicity; parents of adolescents who were VFC versus non-VFC eligible; mothers with low or moderate versus high educational attainment; parents with moderate versus high household income; and parents in suburban or rural versus urban households. Mean differences by subgroup were generally small, ranging from 0.12 for mothers with high versus low educational attainment to 0.27 for white versus Hispanic adolescents.

The three-factor scale indicated that parents generally gave high ratings to Benefits and Trust $(M=8.45, S E=0.03 ; M=9.04, S E=0.02$, respectively) and low ratings to Harms ( $M$ $=3.34, S E=0.04)$. In addition to the subgroup differences identified by the one-factor scale, the three-factor scale suggested less favorable vaccination beliefs among parents of adolescents who were female or from "other" racial/ethnic backgrounds. Differences in confidence were small to moderate, ranging from 0.12 on Trust for mothers with high versus low educational attainment to 0.43 on Harms for Hispanic versus non-Hispanic white adolescents.

\section{DISCUSSION}

Developed using data from a large, nationally-representative sample of parents, our 8-item Vaccination Confidence Scale offers an efficient measure of adolescent vaccination beliefs. Our scale fit the data best when divided into three factors assessing benefits of vaccination, harms of vaccination, and trust in healthcare providers. In terms of health behavior theory, the first two factors correspond as expected to two constructs central to the Health Belief Model (HBM): perceived benefits and barriers. Our third factor, Trust, may be interpreted as a modifying factor that is likely related to cues to action, a third HBM construct that describes triggers needed to prompt behavior. Parents with a high degree of trust in healthcare providers may be more likely to act on cues, such a provider's recommendation, that are known to be highly predictive of adolescent vaccination [10,19-23]. By assessing the factors of Benefits, Harms, and Trust, the Vaccination Confidence Scale can inform interventions aimed at communicating benefits and addressing perceived barriers so as to increase parents' interest in vaccination.

In addition to being brief, the Vaccination Confidence Scale offers consistency. In stratified analyses, the scale maintained good fit across demographic subgroups, suggesting that it can be used to assess vaccination confidence in diverse populations of parents. Such flexibility is important given that parental beliefs and behaviors, including vaccine refusal and delay, vary by characteristics such as race/ethnicity, maternal education, and household income $[1,5-8]$. 
Using the scale, we found that parents' confidence in vaccination was generally high, consistent with prior research [5,6,24-26]. However, we found evidence of lower levels of confidence in several subgroups of parents who may face special barriers to participating in immunization programs. Characteristics including racial/ethnic minority status, lower maternal education, and eligibility for the VFC program were associated with less favorable vaccination beliefs. Given these differences, interventions to improve vaccination confidence may require special attention to factors such as cultural competence and health literacy so as to ensure that programs are accessible to those who stand to benefit from them most.

Targeted interventions may also be valuable, and a further advantage of the three-factor scale is the ability to identify which clusters of beliefs drive subgroup differences in confidence. For example, the three-factor scale suggests that lower confidence among parents of Hispanic versus non-Hispanic white adolescents is due primarily to greater perceived harms of vaccination and lower trust in healthcare providers. By contrast, lower overall scale scores among suburban-and rural-versus urban-dwelling parents appear to be driven by lower perceived benefits of vaccination. Program planners can use these distinctions to develop targeted messages aimed at addressing parents' concerns in an efficient manner.

Strengths of this study include the use of data from NIS-Teen, the largest and most rigorous national survey on adolescent immunization in the United States. Our nationallyrepresentative sample allowed for the development of a robust tool tested with respect to demographic characteristics known to correlate with vaccination beliefs. In addition, the Health Belief Model informed the development of scale items. This use of theory may offset the primary limitation of this study, which was the modest number of items available for scale development. Having a limited item pool is likely the reason for low coefficient alphas for the Harms and Trust factors. Only moderate correlation is to be expected of two-item factors, which can still have practical value in the context of good overall model fit [27-29]. Nevertheless, future iterations of the scale may benefit from further development of the Harms and Trust factors.

Future studies should also seek to assess the Vaccination Confidence Scale in other populations, including parents of younger adolescents. Although we did not find evidence to suggest that vaccination confidence varied by child's age, our sample consisted of parents of 13-to 17-year-olds who were past the age for routine administration of adolescent vaccines. To the extent that parents' beliefs were informed by past experience with adolescent vaccination, our respondents' scale scores may differ from those of parents with younger children not yet eligible for adolescent vaccines. Future research should also assess our scale's ability to predict parental refusal and delay of adolescent vaccines. If successfully validated, our brief measure may hold promise as a clinical screening tool that primary care providers can use to efficiently evaluate the nature and extent of parents' concerns about adolescent vaccination.

In conclusion, our brief, three-factor Vaccination Confidence Scale offers an efficient way to assess vaccination beliefs among parents of adolescent children. This study lends support 
for using our scale in diverse populations of parents, and variation we found in vaccination confidence by demographic factors speaks to the importance of using measures that exhibit desirable statistical properties across different groups. For adolescent vaccines, attaining the widespread coverage achieved for early childhood vaccines will require a concerted effort to address barriers to vaccination, including parental beliefs. Perceived benefits, harms, and trust offer three opportunities for better meeting parents' informational and relational needs so that adolescent vaccination is a decision they can make with confidence.

\section{Acknowledgments}

This study was supported by an Academic Pediatric Association Young Investigator Award and the Cancer Control Education Program at UNC Lineberger Comprehensive Cancer Center (R25 CA57726). The funders did not play a role in study design, data analysis, report writing, or the decision to submit the article for publication.

PR has received HPV vaccine-related grants from Merck Sharp \& Dohme Corp. and from Cervical Cancer-Free America, via an unrestricted educational grant from GlaxoSmithKline. AD serves on an advisory board for Merck, but has not received any research funding from this company. NB has received HPV vaccine-related grants from or been on advisory boards for GlaxoSmithKline and Merck. MG, BM, and ALM have no disclosures to report.

The authors wish to thank Frances McCarty at the National Center for Health Statistics for facilitating access to the dataset.

The findings and conclusions in this paper are those of the authors and do not necessarily represent the views of the Research Data Center, the National Center for Health Statistics, or the Centers for Disease Control and Prevention.

\section{References}

1. Dorell C, Yankey D, Jeyarajah J, Stokley S, Fisher A, Markowitz L, et al. Delay and refusal of human papillomavirus vaccine for girls, National Immunization Survey-Teen, 2010. Clin Pediatr (Phila). 2014; 53(3):261-9. [PubMed: 24463951]

2. Darden PM, Thompson DM, Roberts JR, Hale JJ, Pope C, Naifeh M, et al. Reasons for not vaccinating adolescents: National Immunization Survey of Teens, 2008-2010. Pediatrics. 2013; 131(4):645-51. [PubMed: 23509163]

3. Centers for Disease Control and Prevention (CDC). National and state vaccination coverage among adolescents aged 13-17 years--United States, 2012. MMWR Morb Mortal Wkly Rep. 2013; 62(34): 685-93. [PubMed: 23985496]

4. McRee AL, Brewer NT, Reiter PL, Gottlieb SL, Smith JS. The Carolina HPV Immunization Attitudes and Beliefs Scale (CHIAS): scale development and associations with intentions to vaccinate. Sex Transm Dis. 2010; 37(4):234-9. [PubMed: 19940807]

5. Opel DJ, Taylor JA, Mangione-Smith R, Solomon C, Zhao C, Catz S, et al. Validity and reliability of a survey to identify vaccine-hesitant parents. Vaccine. 2011; 29(38):6598-605. [PubMed: 21763384]

6. Freed GL, Clark SJ, Butchart AT, Singer DC, Davis MM. Parental vaccine safety concerns in 2009. Pediatrics. 2010; 125(4):654-9. [PubMed: 20194286]

7. Smith PJ, Humiston SG, Marcuse EK, Zhao Z, Dorell CG, Howes C, et al. Parental delay or refusal of vaccine doses, childhood vaccination coverage at 24 months of age, and the Health Belief Model. Public Health Rep. 2011; 126 (Suppl 2):135-46. [PubMed: 21812176]

8. Gilkey MB, McRee AL, Brewer NT. Forgone vaccination during childhood and adolescence: findings of a statewide survey of parents. Prev Med. 2013; 56(3-4):202-6. [PubMed: 23295175]

9. Centers for Disease Control and Prevention. About the National Immunization Survey. 2014. Available at: http://www.cdc.gov/nchs/nis/about_nis.htm

10. Reiter PL, Brewer NT, Gottlieb SL, McRee AL, Smith JS. Parents' health beliefs and HPV vaccination of their adolescent daughters. Soc Sci Med. 2009; 69(3):475-80. [PubMed: 19540642] 
11. Benin AL, Wisler-Scher DJ, Colson E, Shapiro ED, Homnboe ES. Qualitative analysis of mothers' decision-making about vaccines for infants: the importance of trust. Pediatrics. 2006; 117:153241. [PubMed: 16651306]

12. Gust DA, Darling N, Kennedy A, Schwartz B. Parents with doubts about vaccines: which vaccines and reasons why. Pediatrics. 2008; 122:718-25. [PubMed: 18829793]

13. Senier L. "It's your most precious thing": worst-case thinking, trust, and parental decision making about vaccination. Social Inquiry. 2008; 78:207-29.

14. Centers for Disease Control and Prevention. Vaccines for Children (VFC) Program. 2014. Available at: http://www.cdc.gov/vaccines/programs/vfc/index.html

15. U.S. Census Bureau. Metropolitan and micropolitan statistical areas. 2014. Available at: http:// www.census.gov/population/metro/

16. Schmitt TA. Current methodological considerations in exploratory and confirmatory factor analysis. J Psychoeduc Assess. 2011; 29:304-21.

17. Hu L, Bentler PM. Cutoff criteria for fit indices in covariance structure analysis: conventional criteria versus new alternatives. Struct Equ Modeling. 1999; 6:1-55.

18. Browne, MW.; Cudeck, R. Alternative ways of assessing model fit. In: Bollen, KA.; Long, JS., editors. Testing Structural Equation Models. Newbury Park, CA: Sage; 1993. p. 136-162.

19. Brewer NT, Gottlieb SL, Reiter PL, et al. Longitudinal predictors of human papillomavirus vaccine initiation among adolescent girls in a high-risk geographic area. Sex Transm Dis. 2011; 38(3): 197-204. [PubMed: 20838362]

20. Small SL, Sampselle CM, Martyn KK, Dempsey AF. Modifiable influences on female HPV vaccine uptake at the clinic encounter level: a literature review. J Am Assoc Nurse Pract. 2013 Epub ahead of print.

21. Allen JD, Othus MK, Shelton RC, et al. Parental decision making about the HPV vaccine. Cancer Epidemiol Biomarkers Prev. 2010; 19(9):2187-98. [PubMed: 20826829]

22. Rosenthal SL, Weiss TW, Zimet GD, Ma L, Good MB, Vichnin MD. Predictors of HPV vaccine uptake among women aged 19-26: importance of a physician's recommendation. Vaccine. 2011; 29(5):890-95. [PubMed: 20056186]

23. Lau M, Lin H, Flores G. Factors associated with human papillomavirus vaccine-series initiation and healthcare provider recommendation in US adolescent females: 2007 National Survey of Children's Health. Vaccine. 2012; 30(20):3112-8. [PubMed: 22425179]

24. McCauley MM, Kennedy A, Basket M, Sheedy K. Exploring the choice to refuse or delay vaccines: a national survey of parents of 6- through 23-month-olds. Acad Pediatr. 2012; 12(5): 375-83. [PubMed: 22921495]

25. Kennedy A, Basket M, Sheedy K. Vaccine attitudes, concerns, and information sources reported by parents of young children: results from the 2009 HealthStyles survey. Pediatrics. 2011; 127 (Suppl 1):S92-9. [PubMed: 21502253]

26. Dempsey AF, Butchart A, Singer D, Clark S, Davis M. Factors associated with parental intentions for male human papillomavirus vaccination: results of a national survey. Sex Transm Dis. 2011; 38(8):769-76. [PubMed: 21336230]

27. Schmitt N. Uses and abuses of coefficient alpha. Psychol Assess. 2009; 8(4):350-3.

28. Sijtsma K. On the use, the misuse, and the very limited usefulness of Cronbach's alpha. Psychometrika. 2009; 74(1):107-20. [PubMed: 20037639]

29. Sijtsma K. Reliability beyond theory and into practice. Psychometrika. 2009; 74(1):169-73. [PubMed: 20037638] 


\section{Highlights}

- We developed a brief, three-factor scale for measuring confidence about adolescent vaccination.

- The scale showed good fit both overall (CFI=0.97) and across demographic subgroups.

- Using the scale to assess a national sample of parents, we found that confidence was generally high.

- However, we found lower confidence among subgroups with lower education or of Hispanic ethnicity. 


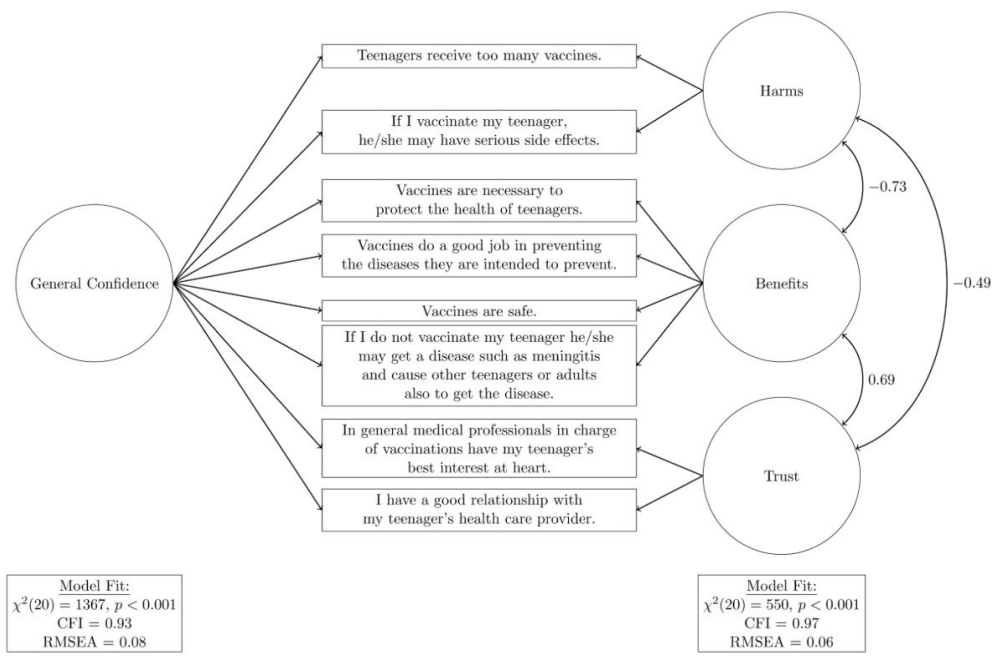

Figure 1. 


\section{Table 1}

Sample characteristics $(N=9,623)$

\begin{tabular}{|c|c|c|}
\hline & $\mathbf{N}$ & $(\%)$ \\
\hline \multicolumn{3}{|l|}{ Child characteristics } \\
\hline \multicolumn{3}{|l|}{ Age } \\
\hline 13 & 1,887 & 19.85 \\
\hline 14 & 1,918 & 19.71 \\
\hline 15 & 1,957 & 19.77 \\
\hline 16 & 2,014 & 21.49 \\
\hline 17 & 1,847 & 19.18 \\
\hline \multicolumn{3}{|l|}{ Sex } \\
\hline Male & 5,003 & 50.97 \\
\hline Female & 4,620 & 49.03 \\
\hline \multicolumn{3}{|l|}{ Race/ethnicity } \\
\hline Non-Hispanic white & 6,892 & 65.93 \\
\hline Non-Hispanic black & 1,116 & 15.94 \\
\hline Hispanic & 837 & 11.18 \\
\hline Other & 778 & 6.96 \\
\hline \multicolumn{3}{|c|}{ Vaccines for Children eligibility } \\
\hline Yes & 2,000 & 23.52 \\
\hline No & 5,636 & 55.13 \\
\hline Not reported & 1,987 & 21.35 \\
\hline \multicolumn{3}{|l|}{ Parent characteristics } \\
\hline \multicolumn{3}{|l|}{ Relationship to child } \\
\hline Mother/female guardian & 7,561 & 77.55 \\
\hline Father/male guardian & 1,605 & 16.66 \\
\hline Grandparent or other & 457 & 5.79 \\
\hline \multicolumn{3}{|l|}{ Mother's age } \\
\hline$\leq 34$ years & 653 & 7.27 \\
\hline $35-44$ years & 3,876 & 43.22 \\
\hline$\geq 45$ years & 5,094 & 49.51 \\
\hline \multicolumn{3}{|l|}{ Mother's education } \\
\hline 12 years or less & 2,552 & 34.44 \\
\hline Some college, no degree & 2,909 & 26.89 \\
\hline College degree or more & 4,162 & 38.68 \\
\hline \multicolumn{3}{|l|}{ Household characteristics } \\
\hline \multicolumn{3}{|l|}{ Region } \\
\hline Northeast & 1,895 & 18.54 \\
\hline Midwest & 2,080 & 22.91 \\
\hline South & 3,562 & 37.76 \\
\hline West & 2,086 & 20.78 \\
\hline Annual income ${ }^{a}$ & & \\
\hline
\end{tabular}

Vaccine. Author manuscript; available in PMC 2015 October 29. 


\begin{tabular}{crr}
\hline & $\mathbf{N}$ & $\mathbf{( \% )}$ \\
\hline Below poverty & 1,093 & 14.39 \\
Above poverty, $\$ 75,000$ & 3,884 & 39.59 \\
$>\$ 75,000$ & 4,272 & 42.17 \\
Not reported & 374 & 3.86 \\
MSA status & & \\
Urban & 3,674 & 34.31 \\
Suburban & 3,672 & 47.85 \\
Rural & 2,277 & 17.84 \\
\hline
\end{tabular}

Note. We report raw frequencies and weighted percentages. Percentages may not total 100 due to rounding.

${ }^{a}$ Poverty level based on 2009 U.S. Census poverty thresholds 


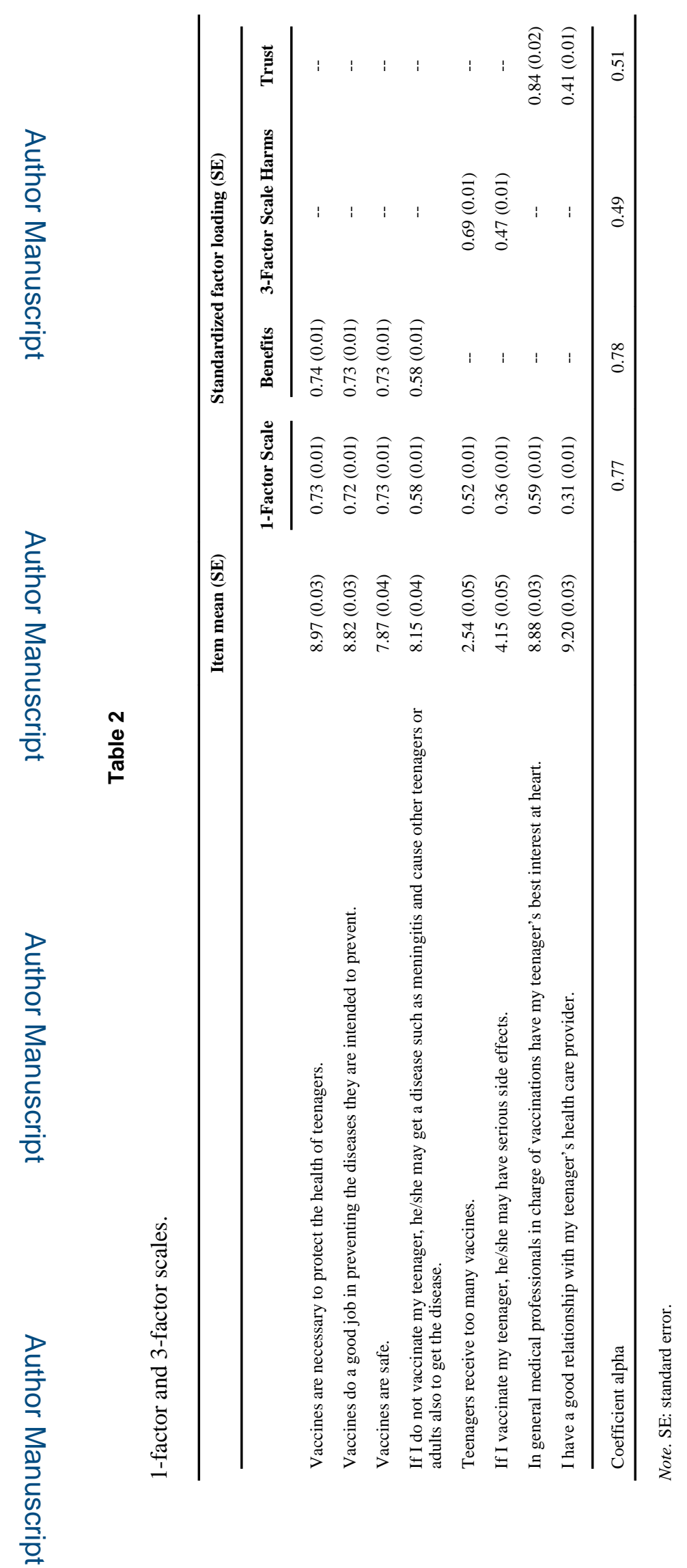

Vaccine. Author manuscript; available in PMC 2015 October 29. 


\section{Table 3}

$\chi^{2}$ tests of fit for nested models.

\begin{tabular}{|c|c|c|c|c|}
\hline & 1-Factor Model $\chi^{2}$ & 3-Factor Model $\chi^{2}$ & $\Delta \chi^{2}$ & Model to Retain \\
\hline Entire sample & 1368 & 550 & 817 & 3 Factors \\
\hline \multicolumn{5}{|l|}{ Child characteristics } \\
\hline \multicolumn{5}{|l|}{ Age } \\
\hline 13 & 226 & 120 & 106 & 3 Factors \\
\hline 14 & 277 & 121 & 156 & 3 Factors \\
\hline 15 & 260 & 110 & 150 & 3 Factors \\
\hline 16 & 351 & 173 & 178 & 3 Factors \\
\hline 17 & 286 & 131 & 155 & 3 Factors \\
\hline \multicolumn{5}{|l|}{ Sex } \\
\hline Males & 692 & 296 & 397 & 3 Factors \\
\hline Females & 686 & 265 & 421 & 3 Factors \\
\hline \multicolumn{5}{|l|}{ Race/ethnicity } \\
\hline Non-Hispanic white & 920 & 416 & 504 & 3 Factors \\
\hline Non-Hispanic black & 208 & 50 & 157 & 3 Factors \\
\hline Hispanic & 141 & 75 & 67 & 3 Factors \\
\hline Other & 156 & 66 & 90 & 3 Factors \\
\hline \multicolumn{5}{|c|}{ Vaccines for Children eligibility } \\
\hline Yes & 357 & 113 & 244 & 3 Factors \\
\hline No & 724 & 348 & 376 & 3 Factors \\
\hline \multicolumn{5}{|l|}{ Parent characteristics } \\
\hline \multicolumn{5}{|l|}{ Mother's education } \\
\hline 12 years or less & 489 & 131 & 358 & 3 Factors \\
\hline Some college, no degree & 393 & 188 & 205 & 3 Factors \\
\hline College degree or more & 540 & 300 & 240 & 3 Factors \\
\hline \multicolumn{5}{|l|}{ Household characteristics } \\
\hline \multicolumn{5}{|l|}{ Annual income } \\
\hline Below poverty & 179 & 58 & 121 & 3 Factors \\
\hline Above poverty, $\$ \$ 75,000$ & 617 & 232 & 386 & 3 Factors \\
\hline$>\$ 75,000$ & 569 & 282 & 289 & 3 Factors \\
\hline \multicolumn{5}{|l|}{ MSA status } \\
\hline Urban & 565 & 209 & 357 & 3 Factors \\
\hline Suburban & 503 & 240 & 263 & 3 Factors \\
\hline Rural & 340 & 163 & 176 & 3 Factors \\
\hline
\end{tabular}

Note: The change in $\chi^{2}$ is statistically significant at the 0.001 -level for 3 degrees of freedom if it exceeds 16.3 . 
Table 4

Mean factor scores across groups.

\begin{tabular}{|c|c|c|c|c|}
\hline & $\begin{array}{l}\text { 1-Factor Scale } \\
\text { Mean (SE) }\end{array}$ & & $\begin{array}{l}\text { 3-Factor Scale } \\
\text { Mean (SE) }\end{array}$ & \\
\hline & & Benefits & Harms & Trust \\
\hline Full sample & $8.15(0.02)$ & $8.45(0.03)$ & $3.34(0.04)$ & $9.04(0.02)$ \\
\hline \multicolumn{5}{|l|}{ Sex } \\
\hline Males (reference) & $8.16(0.04)$ & $8.44(0.04)$ & $3.26(0.06)$ & $9.02(0.03)$ \\
\hline Females & $8.14(0.03)$ & $8.47(0.04)$ & $3.44(0.06)^{*}$ & $9.06(0.04)$ \\
\hline \multicolumn{5}{|l|}{ Race/ethnicity } \\
\hline Non-Hispanic white (reference) & $8.18(0.03)$ & $8.45(0.03)$ & $3.28(0.04)$ & $9.12(0.02)$ \\
\hline Non-Hispanic black & $8.21(0.08)$ & $8.55(0.09)$ & $3.33(0.13)$ & $9.05(0.08)$ \\
\hline Hispanic & $7.91(0.10)^{*}$ & $8.31(0.13)$ & $3.71(0.15)^{*}$ & $8.73(0.11)^{*}$ \\
\hline Other & $8.07(0.09)$ & $8.44(0.08)$ & $3.40(0.17)$ & $8.81(0.10)^{*}$ \\
\hline \multicolumn{5}{|l|}{ Vaccines for Children eligibility } \\
\hline Yes & $8.11(0.06)^{*}$ & $8.47(0.08)$ & $3.52(0.10)^{*}$ & $9.02(0.06)^{*}$ \\
\hline No (reference) & $8.28(0.03)$ & $8.55(0.03)$ & $3.15(0.05)$ & $9.18(0.03)$ \\
\hline \multicolumn{5}{|l|}{ Mother's education } \\
\hline 12 years or less & $8.12(0.04)^{*}$ & $8.48(0.05)$ & $3.51(0.08)^{*}$ & $9.01(0.04)^{*}$ \\
\hline Some college, no degree & $8.07(0.05)^{*}$ & $8.36(0.06)$ & $3.40(0.08)^{*}$ & $8.95(0.06)^{*}$ \\
\hline College degree or more (reference) & $8.24(0.04)$ & $8.49(0.04)$ & $3.16(0.06)$ & $9.13(0.03)$ \\
\hline \multicolumn{5}{|l|}{ Annual income } \\
\hline Below poverty & $8.23(0.08)^{*}$ & $8.66(0.09)^{*}$ & $3.44(0.15)$ & $9.03(0.08)$ \\
\hline Above poverty, $\$ \$ 75,000$ (reference) & $8.05(0.04)$ & $8.36(0.04)$ & $3.47(0.06)$ & $8.96(0.04)$ \\
\hline$>\$ 75,000$ & $8.23(0.04)^{*}$ & $8.48(0.05)$ & $3.16(0.06)^{*}$ & $9.13(0.04)^{*}$ \\
\hline \multicolumn{5}{|l|}{ MSA status } \\
\hline Urban (reference) & $8.24(0.04)$ & $8.59(0.05)$ & $3.30(0.07)$ & $9.10(0.04)$ \\
\hline Suburban & $8.12(0.04)^{*}$ & $8.42(0.04)^{*}$ & $3.33(0.06)$ & $8.99(0.04)$ \\
\hline Rural & $8.04(0.05)^{*}$ & $8.28(0.06)^{*}$ & $3.46(0.09)$ & $9.06(0.05)$ \\
\hline
\end{tabular}

Note. Mean factor scores were not statistically different by child's age. SE: standard error.

* Statistically significant difference from reference group mean. 